\title{
COMBINATION OF BONE MORPHOGENETIC PROTEIN-2 PLASMID DNA WITH CHEMOKINE CXCL12 CREATES AN ADDITIVE EFFECT ON BONE FORMATION ONSET AND VOLUME
}

\author{
F. Wegman ${ }^{1}$, M.T. Poldervaart ${ }^{1}$, Y.J. van der Helm ${ }^{1}$, F.C. Oner ${ }^{1}$, W.J. Dhert ${ }^{1,2}$ and J. Alblas ${ }^{1 *}$ \\ ${ }^{1}$ Dept. of Orthopaedics, G05.228, University Medical Centre Utrecht, P.O.Box 85500, 3508 GA Utrecht, \\ The Netherlands \\ ${ }^{2}$ Faculty of Veterinary Medicine, Utrecht University, Yalelaan 1, 3584 CL Utrecht, The Netherlands
}

\begin{abstract}
Bone morphogenetic protein-2 (BMP-2) gene delivery has shown to induce bone formation in vivo in cell-based tissue engineering. In addition, the chemoattractant stromal cell-derived factor- $1 \alpha$ (SDF-1 $\alpha$, also known as CXCL12) is known to recruit multipotent stromal cells towards its release site where it enhances vascularisation and possibly contributes to osteogenic differentiation. To investigate potential cooperative behaviour for bone formation, we investigated combined release of BMP-2 and SDF-1 $\alpha$ on ectopic bone formation in mice. Multipotent stromal cellseeded and cell-free constructs with BMP-2 plasmid DNA and /or SDF-1 $\alpha$ loaded onto gelatin microparticles, were implanted subcutaneously in mice for a period of 6 weeks. Histological analysis and histomorphometry revealed that the onset of bone formation and the formed bone volume were both enhanced by the combination of BMP-2 and SDF-1 $\alpha$ compared to controls in cell-seeded constructs. Samples without seeded multipotent stromal cells failed to induce any bone formation.

We conclude that the addition of stromal cellderived factor- $1 \alpha$ to a cell-seeded alginate based bone morphogenetic protein-2 plasmid DNA construct has an additive effect on bone formation and can be considered a promising combination for bone regeneration.
\end{abstract}

Keywords: Gene therapy, bone, tissue engineering, bone morphogenetic protein-2, stromal cell-derived factor- $1 \alpha$, multipotent stromal cells, controlled release, animal model.

*Address for correspondence:

J. Alblas, PhD,

UMC Utrecht, Dept. Orthopaedics, Room G05.228

Heidelberglaan 100, 3584 CX Utrecht

P.O. Box 85500, 3508 GA Utrecht, The Netherlands

Telephone number: +31887550294

Fax number: +3130 2510638

E-mail: j.alblas@umcutrecht.nl

\section{Introduction}

Novel strategies are being developed in the field of bone tissue engineering, combining new materials with cell based strategies and growth factor delivery (Asatrian et al., 2015; Gothard et al., 2014). Bone morphogenetic protein-2 (BMP-2) is involved in committing multipotent stromal cells (MSCs) towards the osteogenic lineage and known to induce new bone formation. It is therefore considered to be one of the main growth factors in bone regeneration (Riley et al., 1996). In clinical practice, large amounts of BMP-2 protein are administered to overcome its fast washout due to degradation by proteinases. These high dosages have recently been under debate due to several serious adverse effects - such as vertebral osteolysis, ectopic bone formation, radiculitis and cervical soft tissue swelling (Carragee et al., 2011). As an alternative to the high dosages of BMP-2 protein, strategies that ensure a prolonged delivery of low, physiological concentrations of BMP-2 are now favourably regarded. The delivery of growth factors based on plasmid DNA-based (i.e. non-viral) gene therapy is very attractive, as it results in transient expression of the protein, is easy to manipulate and has shown effectivity for bone formation in a number of carriers, known as gene-activated matrices (GAMs). The ideal gene delivery system is biodegradable and noncytotoxic, and results in a sufficiently high transfection efficiency of the target cells. Recently, a focus on several 3D hydrogel matrices, including collagen sponges and polysaccharides, has emerged (Khan et al., 2012, Curtin et al., 2012; Hosseinkhani et al., 2006; Tierney et al., 2013), that are suitable for osteogenic differentiation and bone formation. We developed an efficient gene delivery system based on the anionic polysaccharide alginate, which is compatible with simultaneous cell seeding and shows very high transfection efficiencies and effectively induces bone formation when supplemented with BMP-2 plasmid DNA (Wegman et al., 2011, 2013; Loozen et al., 2015). Combined with other hydrogels, or in the form of nanoparticles, alginate has previously been used to deliver plasmid DNA (Jain and Amiji, 2012; Krebs et al., 2009; Park et al., 2007), and was successfully applied in bone tissue engineering applications both in vitro and in vivo (Hunt and Grover, 2010; Stevens et al., 2005).

The complexity of bone and its highly vascularised nature demands introduction of multiple biological factors in bone replacement constructs. Besides osteogenic growth factors such as BMP-2, other growth factors such as stromal 
cell-derived factor- $1 \alpha$ (SDF-1 $\alpha$ ) become increasingly important in the field of bone tissue engineering. SDF-1 $\alpha$ is crucial for MSC recruitment to fracture sites and for induction of bone regeneration (Kitaori et al., 2009; Otsuru et al., 2008; Eman et al., 2014). In addition to homing of cells, SDF-1 $\alpha$ has also been shown to induce blood vessel formation in vitro as well as in vivo, which is crucial in regeneration of bone tissue.

As is known from the literature, the need for construct vascularisation is immediate, and therefore a controlled delivery system such as gelatin microparticles (GMPs), which would release the full amount of SDF-1 $\alpha$ in several days, is optimal. The main advantage of GMPs is that growth factor can be loaded onto these biocompatible carriers by simple diffusion; no chemical reactions that can damage the fragile growth factor are necessary. Furthermore, the size of the particles combined with the crosslinking density can tailor the degradation and release rate from the particles (Berkland et al., 2002; Mladenovska et al., 2002), as shown for SDF-1 $\alpha$ (Kimura and Tabata, 2010; Ratanavaraporn et al., 2011). In the design of this study, the aim was to prolong the presence of SDF- $1 \alpha$ at the scaffold site, but at the same time ensure the presence of biologically relevant concentrations early after implantation, which could be achieved by choosing a particle size that would release the growth factor in a matter of days.

When SDF- $1 \alpha$ is combined with BMP-2 protein, a positive effect on bone formation and regeneration has been reported in literature (Chim et al., 2012; Higashino et al., 2011; Ratanavaraporn et al., 2011). The recruitment of MSCs with SDF- $1 \alpha$ or $-\beta$ towards BMP- 2 protein or genetically engineered BMP-2 producing MSCs, induces osteogenic differentiation (Herberg et al., 2013). When both growth factors are released from a combined construct, a synergistic effect on bone formation has even been reported (Ratanavaraporn et al., 2011). The mechanism behind this increased bone formation has been described as a combination of enhanced mobilisation and homing of bone marrow-derived osteoprogenitor cells to the implant, leading to increased numbers of cells available for bone regeneration at ectopic bone implants (Higashino et al., 2011). Furthermore, to increase stability and provide a mineralised surface, on which bone formation can start, biphasic calcium phosphate (BCP) particles are included in the alginate hydrogel-based ectopic constructs in order to promote efficient bone formation (Fedorovich et al., 2011; Yuan et al., 2010).

This study investigates the ability of SDF- $1 \alpha$ proteinloaded gelatin microparticles (G-SDF-1 $\alpha$ ) to attract MSCs towards the BMP-2 plasmid DNA-laden alginate construct, which could lead to gene expression and subsequent osteogenic differentiation of the cells. Because of the promising results with BMP-2 based gene therapy, and the fact that SDF-1 $\alpha$ is a relatively new factor in the field of bone tissue engineering, BMP-2 plasmid DNA is combined with SDF-1 $\alpha$ protein.

\section{Materials and Methods}

\section{Ethics statement}

This study was carried out following the Institutional Guidelines under the Dutch Law ("Wet op de dierproeven") on the use of laboratory animals, in accordance with the recommendations in the Guide for the Care and Use of Laboratory Animals of the National Institutes of Health. The study protocol was approved by the Dutch Ethical Committee for Animal Experimentation (Dier Experimentele Commissie, DEC) of the University of Utrecht, the Netherlands (Permit Number: 06/248).

\section{Alginate gel}

Autoclaved high-viscosity non-medical-grade alginate powder (International Specialty Products, ISP, Memmingen, Germany) was dissolved at a concentration of $10 \mathrm{mg} / \mathrm{mL}$ in alpha minimum essential medium ( $\alpha$-MEM, Gibco, Breda, The Netherlands). The gel was polymerised by adding an equal volume of $100 \mathrm{mM}$ autoclaved $\mathrm{CaCl}_{2}$ supplemented with $10 \mathrm{mM}$ of 4-(2-hydroxyethyl)-1piperazineethanesulfonic acid (HEPES) pH 7.4 (Gibco) for $10 \mathrm{~min} . \mathrm{Ca}^{2+}$-solution was then replaced by expansion medium.

\section{Cell culture}

Goat MSCs were isolated from bone marrow (BM), aspirated from the iliac wings of female Dutch milk goats. The MSCs are isolated by adherence to tissue culture plastic and cultured in expansion medium, containing aMEM (Gibco), supplemented with $15 \%$ (v/v) foetal calf serum (Cambrex, Charles City, IA, USA), $100 \mathrm{U} / \mathrm{mL}$ penicillin, $100 \mu \mathrm{g} / \mathrm{mL}$ streptomycin and $2 \mathrm{mML}$-glutamine (Glutamax, Gibco). The cells were maintained at $37^{\circ} \mathrm{C}$ and $5 \% \mathrm{CO}_{2}$ in a humidified incubator.

\section{Production of gelatin microparticles (GMPs)}

Gelatin microparticles (GMPs) were produced using an adapted protocol first described by Y. Tabata et al. (Young et al., 2005). In short: hydrated gelatin type B (Sigma, St Louis, MO, USA) was added to refined olive oil (Arcos Organics, NJ, USA) to create a water-in-oil emulsion. The emulsion was stirred, rapidly cooled down, washed with acetone and filtered under pressure. Particles were sieved to obtain a size range of $50-75 \mu \mathrm{m}$. Finally, the particles were freeze-dried. SDF-1 $\alpha$ was dissolved at $200 \mu \mathrm{g} / \mathrm{mL}$ in Tris buffered saline (TBS) supplemented with $1 \%$ bovine serum albumin (BSA) and then $10 \mu \mathrm{L}$ was loaded onto $10 \mathrm{mg}$ microspheres overnight at $4{ }^{\circ} \mathrm{C}$ by diffusional loading.

\section{Release of SDF-1 $\alpha$ from GMPs}

SDF-1 $\alpha$ release from GMPs was measured after loading $5 \mu \mathrm{L}$ of SDF-1 $\alpha$-solution (R\&D, MN, USA) per sample $(n=3)$ onto $5 \mathrm{mg}$ GMPs to a total amount of SDF-1 $\alpha$ (final conc. $100 \mathrm{ng} / \mathrm{scaffold}$ ). The microspheres were then incorporated into a $100 \mu \mathrm{L}$ alginate gel $(2 \% \mathrm{w} / \mathrm{v})(\mathrm{IMCD}$, Amersfoort, The Netherlands) that was cross-linked for 5 min with $100 \mathrm{mM} \mathrm{CaCl}_{2}$ solution $[100 \mathrm{mM}$ aqueous 
$\mathrm{CaCl}_{2}$ supplemented with $10 \mathrm{mM}$ of 4-(2-hydroxyethyl)1-piperazineethanesulfonic acid (HEPES) pH 7.4 (Gibco)] to create a plug. $\mathrm{CaCl}_{2}$ was removed and replaced by $1 \mathrm{~mL}$ TBS/BSA $1 \%$ and incubated up to 19 days. At each time point GMPs were centrifuged at $100 \times g$ for $5 \mathrm{~min}$, supernatant was removed and replaced with $1 \mathrm{~mL}$ TBS/ BSA $1 \%$. The supernatant was measured using the standard enzyme linked immune sorbent assay (ELISA, R\&D) protocol.

\section{Preparation in vivo implants}

Four different MSC-seeded constructs were made, each consisting of $200 \mu \mathrm{L}$ alginate $(10 \mathrm{mg} / \mathrm{mL}), 10^{7}$ goat MSCs/ $\mathrm{mL}$ gel, $20 \%$ (w/v) BCP particles (size 106-212 $\mu \mathrm{m}$ ) and $10 \mathrm{mg}$ gelatin microparticles (GMPs). The BCP particles consisted of $80 \% \pm 5 \%(\mathrm{w} / \mathrm{v})$ hydroxyapatite and $20 \pm$ $5 \%(\mathrm{w} / \mathrm{v}) \beta$-tricalcium phosphate, and total porosity was $70 \pm 5 \%$, macroporosity $55 \pm 5 \%$ and microporosity 20 $\pm 5 \%$ (Xpand biotechnology, Bilthoven, Netherlands). The BCP particles were cleaned in an ultrasonic bath and sterilised by autoclave. The BMP-2 plasmid DNA construct contained the full-length human recombinant BMP-2 cDNA, whose expression was driven by the cytomegalovirus promoter in pcDNA3.1 (Invitrogen) (Wegman et al., 2011).

The four different constructs further received: 1) empty GMPs; 2) $10 \mu \mathrm{g} / \mathrm{mL}$ of pBMP-2 and empty GMPs (in short BMP-2); 3) $10 \mu \mathrm{g} / \mathrm{mL}$ of pBMP-2 plus $10 \mathrm{mg}$ GMPs loaded with $2 \mu \mathrm{g}$ SDF-1 $\alpha$ (in short: BMP-2/GSDF-1 $\alpha$ ); or 4) $10 \mathrm{mg}$ G-SDF-1 $\alpha$ (in short: G-SDF-1 $\alpha$ ). The alginate constructs were polymerised and implanted the same day. In groups 1 and 2 GMPs were loaded with TBS overnight and added before polymerisation, and in group 3 and 4 GMPs were loaded overnight with $10 \mu \mathrm{L}$ TBS containing $2 \mu \mathrm{g}$ of SDF- $1 \alpha$, which is considered an optimal dose in the literature (Higashino et al., 2011). All implants were subsequently polymerised with $1 \mathrm{~mL}$ of $100 \mathrm{mM}$ autoclaved $\mathrm{CaCl}_{2}$, supplemented with $10 \mathrm{mM}$ of 4-(2-hydroxyethyl)-1-piperazineethanesulfonic acid (HEPES pH 7.4, Gibco), for 10 min before implantation. The supernatant was removed and all implants were kept in MSC culture medium until implantation. The four different unseeded constructs were made according to the same protocol except for the addition of goat MSCs.

\section{Animals and implantation}

Female nude mice (Hsd-cpb:NMRI-nu, Harlan) were anaesthetised with $1.5 \%$ isoflurane, after which 5 separate subcutaneous dorsal pockets per mouse were created. The implants ( $n=6$ per group) were each placed in a pocket with a small surgical spoon and afterwards the skin was sutured back together. The animals were postoperatively treated with the analgesic buprenorphine, administered subcutaneously (s.c.) $(0.05 \mathrm{mg} / \mathrm{kg}$; Temgesic, Schering-Plough) and housed together at the Central Laboratory Animal Institute, Utrecht University. Due to ethical reasons female mice were chosen, since they can be housed in groups. At 3 weeks after implantation calcein green was administered s.c. (10 mg/kg; Sigma, Zwijndrecht, Netherlands), and at 4 weeks after implantation xylenol orange was administered s.c. (30 mg/kg, Merck, Amsterdam, Netherlands). Six weeks after implantation the animals were terminated by cervical dislocation.

\section{Explantation and embedding}

After euthanasing the animals, the constructs were retrieved to analyse general morphology, transfection and bone histomorphometry. After a dorsal $\mathrm{H}$-incision samples were clearly visible and dissected from the animals. They were cut in half for processing. One part was fixed overnight in $4 \%$ (v/v) formalin containing $100 \mathrm{mM} \mathrm{CaCl}_{2}$ and processed for $5 \mu \mathrm{m}$ thick decalcified paraffin sections through alcohol dehydration series. The other half was fixed in $4 \%$ formalin, dehydrated by ethanol series and embedded in polymethylmethacrylate (MMA), after which $10 \mu \mathrm{m}$ thick sections were cut from the centre and side of each implant using a sawing microtome (Leica, Nussloch, Germany). These sections remained unstained for fluorochrome analysis. The presence of each fluorochrome label was scored for all implants.

\section{BMP-2 immunohistochemistry}

To detect BMP-2 producing cells in the implants, immunohistochemistry was performed. Sections were permeabilised with Triton X-100 and blocked in $3 \%$ $\mathrm{H}_{2} \mathrm{O}_{2}$ for $10 \mathrm{~min}$ and $5 \% \mathrm{BSA}$ for $30 \mathrm{~min}$. Sections were washed using Tris buffered saline with $100 \mathrm{mM} \mathrm{CaCl}_{2}$ $\left(\mathrm{TBS} / \mathrm{CaCl}_{2}\right)$. Antigen retrieval was performed using $1 \mathrm{~mL}$ trisodium citrate $2.94 \mathrm{~g} / \mathrm{L}$, which was heated from $37^{\circ} \mathrm{C}$ to $80{ }^{\circ} \mathrm{C}$ in $30 \mathrm{~min}$. Cooled down sections were blocked with $\mathrm{TBS} / \mathrm{CaCl}_{2}$ with $5 \% \mathrm{BSA}$ for $30 \mathrm{~min}$ at room temperature (RT). Sections were subsequently incubated with $5 \mu \mathrm{g} / \mathrm{mL}$ rabbit-anti-human BMP-2 (LifeSpan Bio, LS-C43125) overnight at $4^{\circ} \mathrm{C}$, and as secondary antibody $13 \mu \mathrm{g} / \mathrm{mL}$ goat-anti-rabbit IgG-HRP (Invitrogen, 624320) was incubated for $1 \mathrm{~h}$ at RT. The staining was developed with diaminobenzidine (DAB) and Mayer's haematoxylin was used for counterstaining. All antibodies were diluted in $\mathrm{TBS} / \mathrm{BSA}$ with $\mathrm{CaCl}_{2}$.

\section{Safranin O staining}

Sections were deparaffinised and incubated with haematoxylin (Weigert's) for $5 \mathrm{~min}$. After washing in running tap water, sections were dipped in distilled water and counterstained in $0.4 \%(\mathrm{w} / \mathrm{v})$ Fast green solution. Sections were rinsed in $0.17 \mathrm{M}$ acetic acid until the colour no longer runs and counterstained again in freshly prepared $0.125 \%$ (w/v) Safranin O (Merck) staining dissolved in distilled water. After a short dehydration protocol, sections were mounted in Depex. The staining was performed on duplicate sections. Two independent observers, blinded for the study groups, scored the presence or absence of cartilage.

\section{Bone histomorphometry}

High-resolution digital images were made from HE stained sections for histomorphometric analysis. From each implant, images from three predefined positions were acquired and analysed in duplicate. Bone and scaffold were pseudo-coloured using Adobe Photoshop CS3. Afterwards, histomorphometry was performed using Axiovision software (version 4.8; Zeiss, Nussloch, Germany). A 


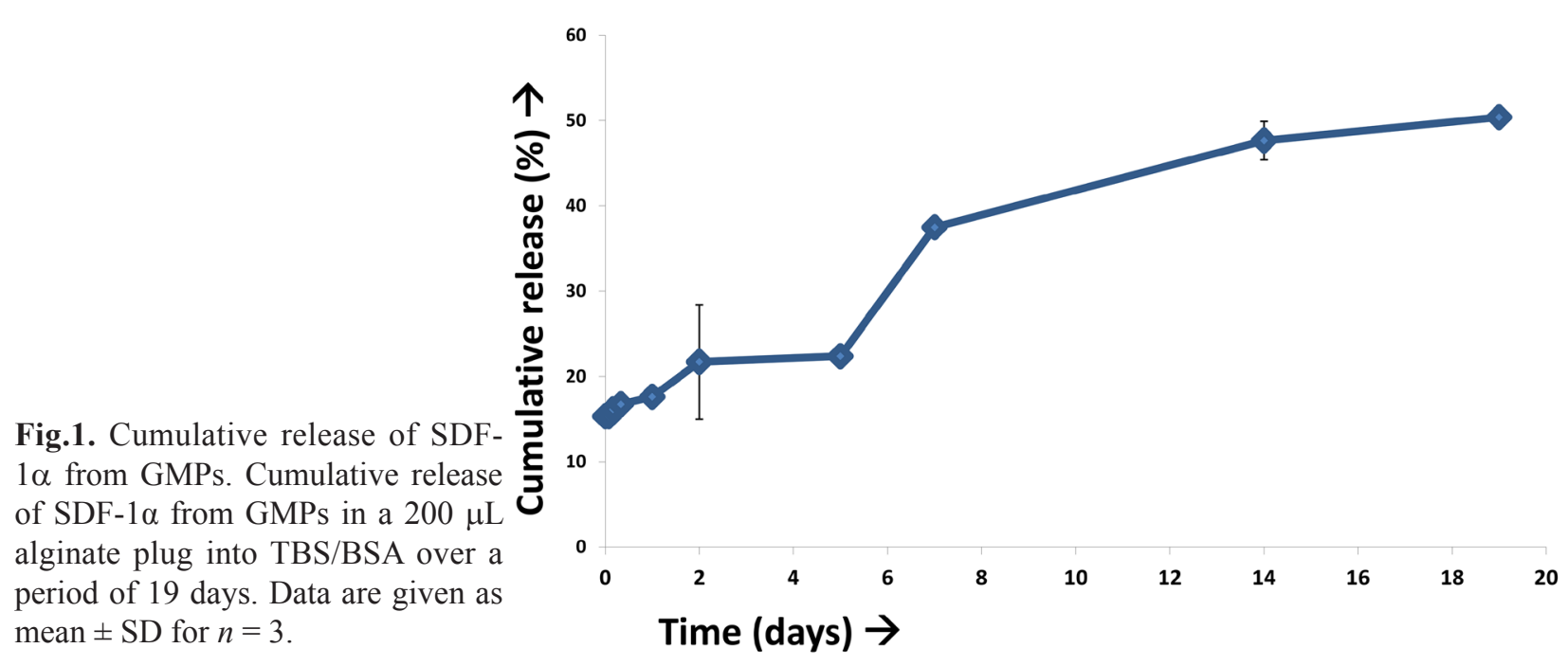

custom macro was used to measure the region of interest, the area of scaffold, and the area of bone. This allowed the quantification of the percentage bone in available space, indicated by bone area \% [ = (bone area/(total area-scaffold area) $\times 100]$. All samples and photographs were analysed blinded by two observers.

\section{Fluorochrome analysis}

The fluorochrome markers were analysed from the unstained sections $(n=3)$ using a fluorescence microscope (E600, Nikon) equipped with a quadruple filter block (XF57, dichroic mirror 400, 485, 558 and $640 \mathrm{~nm}$, Omega optics, Brattleboro, VT). Fluorochromes incorporated in the newly formed bone were scored for presence/absence. To discriminate between the bone and the underlying scaffold, the fluorescence signal was compared to the bright field signal.

\section{Statistics}

The statistical significance of differences between the bone volume percentage of empty GMPs, BMP-2, G-SDF- $1 \alpha$ and BMP-2/ G-SDF-1 $\alpha$ groups was assessed using a randomised block design. Multiple comparisons were generated using a LSD post-hoc correction to calculate the $p$-values. A $p$-value of $<0.05$ was considered significant.

\section{Results}

In order to simultaneously deliver the chemokine SDF$1 \alpha$ and the osteogenic stimulus BMP-2, the previously described gene delivery technique where BMP-2 plasmid DNA was incorporated in an alginate hydrogel, which acts as both a transfection agent and controlled release system, was used (Wegman et al., 2011). This provides a transfection efficiency of around $60 \%$ and a long-lasting production and release of BMP-2 up to a period of several weeks. In vivo BCP particles are added as a bone-forming core and in the current study GMPs containing SDF-1 $\alpha$ were added to these alginate-based BMP-2/BCP containing constructs.
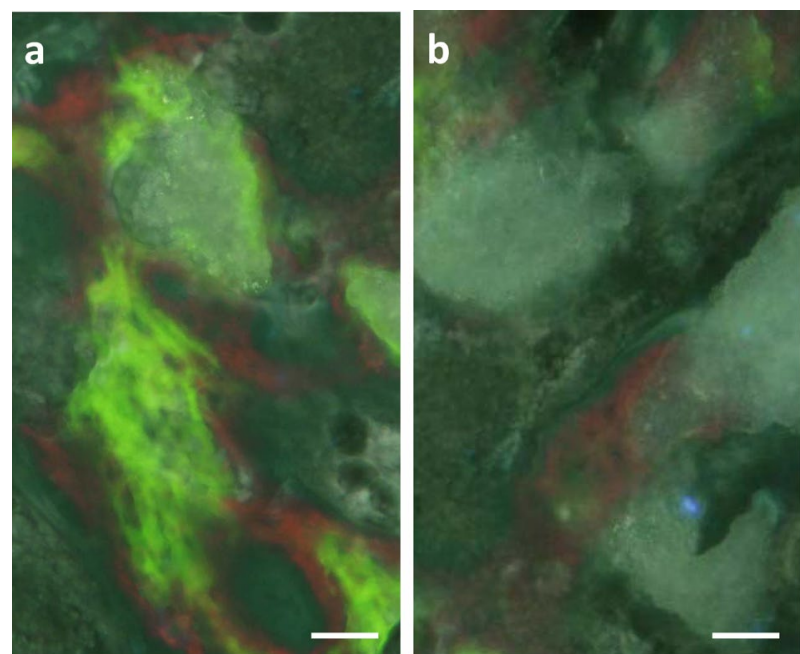

\begin{tabular}{|l|l|l|}
\hline & Week 3 & Week 4 \\
\hline Empty GMPs & 0 & 0 \\
\hline BMP-2 & 0 & 17 \\
\hline G-SDF-1 $\alpha$ & 0 & 0 \\
\hline BMP-2/G-SDF-1 $\alpha$ & 33 & 67 \\
\hline
\end{tabular}

Fig.2. Bone onset analysed by fluorochrome analysis. Detection of Calcein green, administered at week 3 after implantation and Xylenol orange, administered at week 4 after implantation. a) Combined BMP-2/G-SDF-1 $\alpha$ sample displaying both the 3 and 4 week label. b) Empty GMP or G-SDF-1 $\alpha$ sample, no fluorochromes present. The percentage of samples containing the fluorochrome is listed. Scale bar represents $25 \mu \mathrm{m}$.

First, the in vitro SDF-1 $\alpha$ release profile from the alginate plugs was investigated. After 19 days the alginate plugs were still intact and $50 \%$ of the loaded protein was gradually released from the plugs (Fig. 1).

Subsequently, GMP containing constructs were implanted subcutaneously in mice for 6 weeks to investigate whether host MSCs can be recruited to cell-free constructs by chemokine attraction. These could possibly be transfected with the plasmid DNA, produce BMP-2 as a result of the transfection and eventually induce bone 


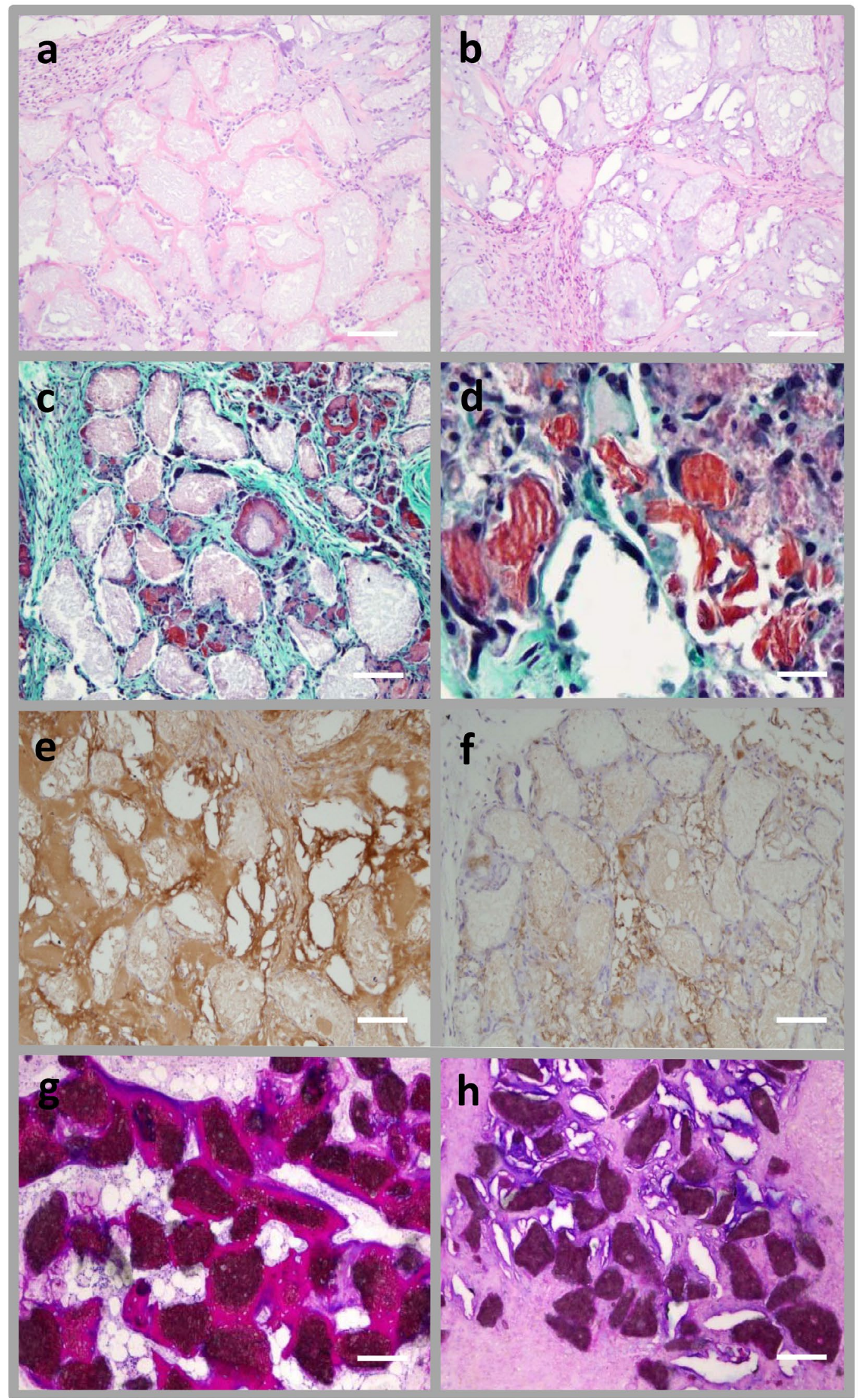

Fig.3. General histology and bone formation of MSC seeded samples. a, b) HE staining, bone in pink, a)BMP-2/GSDF-1 $\alpha$ sample, b) control sample. c, d) Safranin O staining, fibrous tissue in green, BCP in pink and alginate remnants in red. c) representative sample containing alginate remnants, overview. d) representative sample containing alginate remnants, detail. e, f) Collagen I immunocytochemistry (in brown). e) BMP-2/G-SDF-1 $\alpha$ sample, f) control sample. g, h) Basic fuchsin/methylene blue staining, bone in pink. g) BMP-2/G-SDF-1 $\alpha$ sample, h) control sample. a-c and e-h) Representative samples were chosen for each group, scale bar represents $100 \mu \mathrm{m}$, d) scale bar represents $20 \mu \mathrm{m}$. 
formation. This process might be optimised and accelerated since vascularisation, important for bone formation can be stimulated by SDF-1 $\alpha$ as well (Eman et al., 2014).

MSC seeded constructs are also implanted to investigate whether bone formation can be enhanced due to a synergistic effect of the BMP-2/G-SDF- $1 \alpha$ combination (Ratanavaraporn et al., 2011). After explantation and processing the general morphology of both seeded and unseeded samples was determined by several histological stainings such as haematoxylin/eosin (HE), Safranin O and basic fuchsin/methylene blue. In the unseeded constructs no differences could be detected in scoring of vessel-like structures, number of recruited cells or fibrous tissue formed around the BCP particles (Fig. 3a, b). All groups, both seeded and unseeded, contained some samples with remnants of the alginate present (Fig. 3c, d). However, no presence of the GMPs was detected. Furthermore, no signs of an inflammatory response were present. Fibrous capsule formation was hardly present and if detected, presented with a maximum of 5 cell layers thick. In terms of bone formation, all unseeded samples, with or without the presence of BMP-2 or SDF-1 $\alpha$, lacked any signs of bone formation. However, the MSC-seeded experimental setup did result in bone formation. Therefore, we will focus on the results from the MSC seeded samples and mainly discuss the results for tissue responses, onset of bone formation and bone histomorphometry in the following paragraphs.

To determine possible differences in bone formation onset, fluorochrome incorporation was analysed. Except for the BMP-2/G-SDF-1 $\alpha$ group and one sample in the BMP-2 group, no fluorochromes were detected (Fig. 2). Since hardly any of the week 3 and week 4 labels where present in the constructs, the onset of bone formation must have been between week 4 and 6 after implantation in most animals. In the BMP-2/G-SDF-1 $\alpha$ group however, $33 \%$ of the samples contained the orange label, but not the green week 3 label. This indicates that bone formation occurred between week 3 and week 4 in these samples, which is earlier than the bone onset in the single growth factor groups (Fig. 2).

To investigate not only the onset but also the amount of newly formed bone as a result of combined SDF-1 $\alpha$ and BMP-2 release, matrix and bone formation have been analysed by histomorphometry. In contrast to $\mu \mathrm{CT}$, this allows discrimination between bone and ceramic scaffold. In the BMP-2/G-SDF- $1 \alpha$ constructs, abundant collagen I staining was seen compared to the empty GMP, BMP-2 or G-SDF-1 $\alpha$ samples (Fig. 3e, f). Besides collagen, BMP-2 was detected in both the control samples and BMP-2/GSDF- $1 \alpha$ constructs, as a result of antibody cross-species reactivity for BMP-2. Nevertheless, a higher intensity of BMP-2 staining was present in the samples with BMP-2 plasmid DNA and SDF-1 $\alpha$ loaded GMPs (Fig. 5), which corresponds well to the amount of bone that was found in these samples. To indicate bone volume differences in the seeded implants, bone histomorphometry was performed on basic fuchsin/methylene blue stained MMA sections for quantification of bone area $\%$, which by extrapolation are indicative of bone volumes (Fig. 3g, h). This revealed that all groups contained several samples showing new bone. In

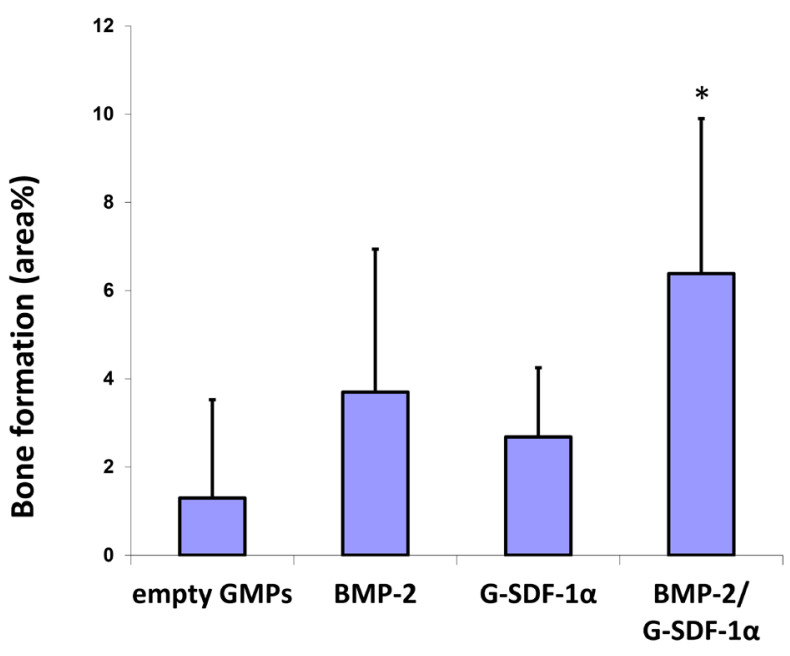

Fig.4. Quantification of bone formation in MSC seeded constructs (3 ROI/ sample, 2 sections per sample, $n=6$ mice). Analysis of bone area \% (for details see Materials and Methods) after an implantation period of 6 weeks. $*$ = significantly different from control and single growth factor groups, $p<0.05$, data are given as mean $\pm \mathrm{SD}$ for $n=6$.

the empty GMP samples however, very small volumes were detected. In the groups with either BMP-2 or G-SDF-1 $\alpha$, bone formation was clearly present. However, the BMP$2 / \mathrm{G}-\mathrm{SDF}-1 \alpha$ constructs induced significantly more bone formation, compared to the control or single growth factor groups. An average of 6.4 area \% was detected (Fig. 4).

\section{Discussion}

This study investigated the use of SDF- $1 \alpha$ for bone tissue engineering using alginate/BMP-2 plasmid DNA laden constructs. Using non-viral plasmid DNA based gene therapy is a promising new strategy to deliver growth factors locally for a longer period of time, without the use of supraphysiological doses (Wegman et al., 2013). However, most non-viral systems fail to induce high transfection efficiencies. Our previous studies have shown that by using alginate hydrogel, the advantages of using plasmid DNA can be combined with high transfection efficiencies up to $60 \%$. Therefore, in this study we investigated the ability of SDF-1 $\alpha$ to sufficiently induce the homing of host MSCs towards unseeded BMP-2 plasmid DNA containing alginate constructs. From previous experiments it is known that MSCs are able to take up and express the BMP-2 cDNA, thereby inducing osteogenic differentiation in vitro and subsequent bone formation in vivo. In this study, goat MSCs have been used to enable proceeding to larger animal models such as goats, in order to treat more clinically relevant osteogenic defects in the future. Because immunocompromised mice were chosen, the goat MSCs were not rejected after implantation, and could differentiate towards osteoblasts with subsequent bone formation ectopically. This set-up allows investigating in detail the growth factors (in this case BMP-2 and SDF-1 $\alpha$ ) that guide bone formation, and perform optimisation and 


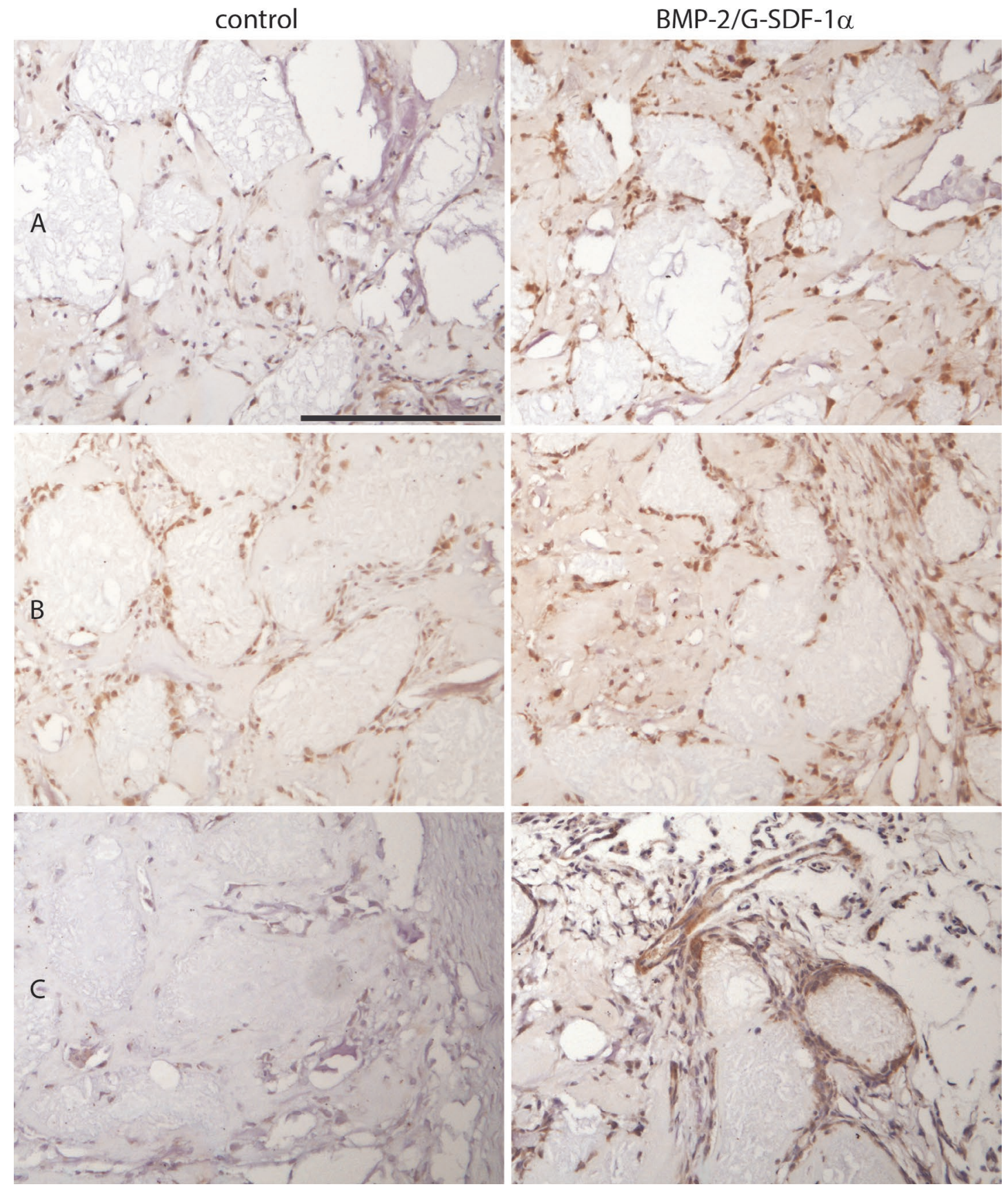

Fig.5. Expression of BMP-2 in MSC seeded constructs. BMP-2 immunohistochemistry performed on control samples and BMP-2/G-SDF- $1 \alpha$ samples after an implantation period of 6 weeks. A,B,C indicate three different mice, scale bar represents $200 \mu \mathrm{m}$.

feasibility studies before moving to more challenging and costly large animal models.

The implanted constructs consisted of alginate plugs combined with BCP particles and GMPs loaded with SDF$1 \alpha$. The alginate provides the basis of the construct and acts as a transfection agent for BMP-2 plasmid DNA. As known from literature and previous experiments, alginate will degrade within the implantation period of 6 weeks due to an outward flux of the crosslinking ions, allowing a complete growth factor release (Rowley et al., 1999). The BCP particles were added to provide a mineralised surface for bone formation to start on. These particles, when combined with MSCs, are known to promote osteogenesis in previous studies (Geuze et al., 2009a; LeGeros et al., 2003). The GMPs were chosen as a slow release system for SDF-1 $\alpha$. Microsphere degradation was shown to occur within 28 days in vitro when incubated in simulated body fluid (SBF) (Leeuwenburgh et al., 2010). When implanted subcutaneously in mice, gelatin microspheres will remain present at least for 4 weeks, during which time they have released most of the loaded growth factors (Poldervaart et al., 2013). SDF-1 $\alpha$ release has been studied in vivo before and can be successfully released over a period of 3 weeks from GMPs (Kimura and Tabata, 2010). Because, in this study, loaded GMPs are embedded in alginate-based constructs for implantation in mice, release experiments 
were conducted on these alginate/GMP constructs (Fig. 1). Since previous studies showed no influence of BCP on SDF-1 $\alpha$ release, this was not included into the experimental setup (data not shown).

After 19 days a sustained release was still apparent. About $50 \%$ of all incorporated SDF-1 $\alpha$ was released by then (Fig. 1). This seems rather slow for a chemokine which is supposed to attract MSCs to the construct directly after implantation. However, in vivo release is expected to be faster than in vitro release, presumably due to faster degradation of the alginate construct (Kempen et al., 2009). This is substantiated by the observation that the constructs were completely intact after 19 days of incubation in vitro, whereas after in vivo implantation only some fragmented alginate but no GMPs were detected.

In the explanted samples, no differences were found in histological scorings of general morphology and immunological processes such as fibrous capsule formation or the presence of multinucleated giant cells (Fig. 3a, b). And even though most SDF-1 $\alpha$ is thought to be released, no increase in vessel formation was observed in either seeded or unseeded samples at this time point. This finding differs from accounts in the literature, where the presence of SDF-1 $\alpha$ increased vessel formation (Jin et al., 2006; Kimura and Tabata, 2010). It is possible that the alginate surrounding the GMPs loaded with SDF-1 $\alpha$ prevented or delayed vessel ingrowth. Another possibility is that the timeframe of implantation ( 6 weeks) exceeds the timeframe in which vascular changes can be detected, since these are most often seen during early stages of the implantation period. However, the amount of BMP-2 produced by the cells as a result of the addition of BMP-2 plasmid DNA and SDF- $1 \alpha$ loaded GMPs appears to be increased. When comparing the results of a BMP-2 immunohistochemistry staining for the control and BMP-2/G-SDF- $1 \alpha$ samples $(n=3)$, the staining appears to be darker and present in more cells. Unfortunately, it is not possible to discriminate between endogenous BMP-2 and the transgene product, due to cross-species recognition by anti-BMP-2 antibodies. From these results and our previous work (Wegman et al., 2011; Loozen et al., 2015), in which we determined BMP-2 production in vitro up to $2 \mathrm{ng} / \mathrm{mL}$, we infer that sufficient amounts of BMP-2 are produced for osteogenicity to occur.

To investigate whether SDF-1 $\alpha$ and/or BMP-2 had an effect on the onset of bone formation in cell-seeded constructs, fluorochrome analysis was performed (Fig. 2). Even though we found some bone in the empty GMP and G-SDF- $1 \alpha$ laden groups, no fluorochromes were detected - with the exception of one sample in the BMP2 plasmid DNA group, displaying the week 4 label. This indicates that the start of bone formation mainly occurred after the administration of the week 4 fluorochrome but before explantation at week 6 . The samples containing both growth factors and expressing the highest amount of bone, showed both the week 3 and week 4 fluorochrome label in several samples. This indicates that the combination of BMP-2 and SDF- $1 \alpha$ advances bone onset compared to the other three groups. Bone is first formed sometime around 3 to 4 weeks after implantation. To our knowledge this effect of the combined growth factors has not yet been reported before.
Consistent with the fluorochrome analysis, no bone was present in any of the unseeded constructs. In the in vitro release study we found that SDF-1 $\alpha$ was released; however, in vivo the constructs contained plasmid DNA as well as $\mathrm{BCP}$ granules. It is very unlikely that the presence of $\mathrm{BCP}$ affected growth factor release, since the BCP granules had not been soaked in growth factor. Since we know from literature that SDF-1 $\alpha$ is able to recruit MSCs (Chim et al., 2012; Eman et al., 2014), it is possible that insufficient amounts MSCs have been recruited towards the constructs. Therefore, the cell loading limit to obtain bone formation is not reached or the release of SDF-1 $\alpha$ exceeded the time frame of implantation (Wernike et al., 2010).

In the MSC-seeded groups, clear differences were observed between all implanted groups. Because BCP particles, known to promote osteogenesis when combined with MSCs, were added to the implanted constructs, some bone had formed in the control samples, which is in accordance with previous results (Geuze et al., 2009b; LeGeros et al., 2003). Bone also had formed in the groups containing either BMP-2 plasmid DNA or G-SDF- $1 \alpha$ alone, but even though a higher average of bone volume was detected, no significant differences in bone formation occurred compared to the control samples. However, when BMP-2 plasmid DNA and SDF- $1 \alpha$ are combined, an in literature described additive effect occurs due to the combination of osteogenic cell recruitment from the circulation with SDF-1 $\alpha$ and induction of in vivo bone formation in the presence of BMP-2 (Fig. 4). This increase in bone formation was consistent with an increase in collagen I (Fig. 3e, f). These results confirm previous results describing bone formation as a result of BMP-2 plasmid DNA based bone tissue engineering. BMP-2 is mainly active in the first few weeks of fracture healing, and given the fact that bone formation is induced successfully at an ectopic location, combined with the results of previous in vitro release studies, it is likely that this biological release pattern is approached. SDF-1 $\alpha$ is involved in cell recruitment towards an inflammatory site, or the site of release as is the case in this study, and is therefore needed during the early stages after implantation. SDF-1 $\alpha$ could be measured in vitro for a period of at least 19 days, but it is known that in vivo growth factor release occurs faster than in vitro, due to presence of proteinases (Kempen et al., 2008). In this experiment we aimed for a presence of SDF-1 $\alpha$ during the first 2 weeks after implantation. Based on literature in which a presence of SDF-1 $\alpha$ from a gelatin hydrogel for 21 days in vivo has been shown (Kimura and Tabata, 2010), combined to the induced bone formation in our combined growth factor construct we argue that both BMP-2 and SDF-1 $\alpha$ have been present for a biologically relevant period of time in this set of experiments.

\section{Conclusions}

In conclusion, the combination of G-SDF- $1 \alpha$ and pBMP-2 plasmid DNA in an alginate based construct induced an additive effect on bone formation, leading to an advanced onset of bone formation and a significantly higher bone volume. This effect was only seen in the presence of seeded 
MSCs. When SDF-1 $\alpha$ was added to cell-free alginate based, BMP-2 plasmid DNA laden construct, osteogenic progenitor cells were not sufficiently recruited from the circulation in order to induce uptake and expression of BMP-2, induce osteogenic differentiation and eventually bone formation in a six weeks implantation period. Therefore, we conclude that addition of SDF- $1 \alpha$ in the presence of seeded MSCs further optimises bone regeneration in vivo of previously established BMP-2 plasmid DNA-laden alginate constructs.

\section{Acknowledgements}

The authors gratefully acknowledge the support of the Smart Mix Program of the Netherlands Ministry of Economic Affairs and the Netherlands Ministry of Education, Culture and Science. Kelly van Deventer is thanked for her contribution to the performed histology.

\section{References}

Asatrian G, Pham D, Hardy WR, James AW, Peault B. (2015) Stem cell technology for bone regeneration: current status and potential applications. Stem Cells Cloning 10: 39-48.

Berkland C, King M, Cox A, Kim K, Pack DW (2002) Precise control of PLG microsphere size provides enhanced control of drug release rate. J Control Release 82: 137-147.

Carragee EJ, Hurwitz EL, Weiner BK (2011) A critical review of recombinant human bone morphogenetic protein-2 trials in spinal surgery: emerging safety concerns and lessons learned. Spine J 11: 471-491.

Chim H, Miller E, Gliniak C, Alsberg E (2012) Stromalcell-derived factor (SDF) 1-alpha in combination with BMP-2 and TGF-beta1 induces site-directed cell homing and osteogenic and chondrogenic differentiation for tissue engineering without the requirement for cell seeding. Cell Tissue Res 350: 89-94.

Curtin CM, Cunniffe GM, Lyons FG, Bessho K, Dickson GR, Duffy GP, O'Brien FJ (2012) Innovative collagen nano-hydroxyapatite scaffolds offer a highly efficient non-viral gene delivery platform for stem cellmediated bone formation. Adv Mater 24: 749-754.

Eman RM, Oner FC, Kruyt MMP, Dhert W, Alblas J (2014) Stromal cell-derived factor-1 stimulates cell recruitment, vascularization and osteogenic differentiation. Tissue Eng Part A 20: 466-473.

Fedorovich NE, Wijnberg HM, Dhert WJ, Alblas J (2011) Distinct tissue formation by heterogeneous printing of osteo- and endothelial progenitor cells. Tissue Eng Part A 17: 2113-2121.

Geuze RE, Everts PA, Kruyt MC, Verbout AJ, Alblas J, Dhert WJ (2009a) Orthotopic location has limited benefit from allogeneic or autologous multipotent stromal cells seeded on ceramic scaffolds. Tissue Eng Part A 15: 3231 3239 .

Geuze RE, Wegman F, Oner FC, Dhert WJ, Alblas J (2009b) Influence of endothelial progenitor cells and platelet gel on tissue-engineered bone ectopically in goats. Tissue Eng Part A 15: 3669-3677.

Gothard D, Smith EL, Kanczler JM, Rashidi H, Qutachi O, Henstock J, Rotherham M, El Haj A, Shakesheff KM, Oreffo RO (2014) Tissue engineered bone using select growth factors: A comprehensive review of animal studies and clinical translation studies in man. Eur Cell Mater 28: 166-207.

Herberg S, Shi X, Johnson MH, Hamrick MW, Isales CM, Hill WD (2013) Stromal cell-derived factor-1beta mediates cell survival through enhancing autophagy in bone marrow-derived mesenchymal stem cells. PLoS ONE 8: e58207.

Higashino K, Viggeswarapu M, Bargouti M, Liu H, Titus L, Boden SD (2011) Stromal cell-derived factor-1 potentiates bone morphogenetic protein-2 induced bone formation. Tissue Eng Part A 17: 523-530.

Hosseinkhani H, Yamamoto M, Inatsugu Y, Hiraoka Y, Inoue S, Shimokawa H, Tabata Y (2006) Enhanced ectopic bone formation using a combination of plasmid DNA impregnation into 3-D scaffold and bioreactor perfusion culture. Biomaterials 27: 1387-1398.

Hunt NC, Grover LM (2010) Cell encapsulation using biopolymer gels for regenerative medicine. Biotechnol Lett 32: 733-742.

Jain S, Amiji M (2012) Tuftsin-modified alginate nanoparticles as a noncondensing macrophage-targeted DNA delivery system. Biomacromolecules 13: 1074-1085.

Jin DK, Shido K, Kopp HG, Petit I, Shmelkov SV, Young LM, Hooper AT, Amano H, Avecilla ST, Heissig B, Hattori K, Zhang F, Hicklin DJ, Wu Y, Zhu Z, Dunn A, Salari H, Werb Z, Hackett NR, Crystal RG, Lyden D, Rafii S (2006) Cytokine-mediated deployment of SDF-1 induces revascularization through recruitment of CXCR4+ hemangiocytes. Nat Med 12: 557-567.

Kempen DH, Lu L, Classic KL, Hefferan TE, Creemers LB, Maran A, Dhert WJ, Yaszemski MJ (2008) Noninvasive screening method for simultaneous evaluation of in vivo growth factor release profiles from multiple ectopic bone tissue engineering implants. J Control Release 130: 15-21.

Kempen DH, Lu L, Heijink A, Hefferan TE, Creemers LB, Maran A, Yaszemski MJ, Dhert WJ (2009) Effect of local sequential VEGF and BMP-2 delivery on ectopic and orthotopic bone regeneration. Biomaterials 30: 2816-2825.

Khan W, Hosseinkhani H, Ickowicz D, Hong PD, Yu DS, Domb AJ (2012) Polysaccharide gene transfection agents. Acta Biomater 8: 4224-4232.

Kimura Y, Tabata Y (2010) Controlled release of stromal-cell-derived factor-1 from gelatin hydrogels enhances angiogenesis. J Biomater Sci Polym Ed 21: $37-$ 51.

Kitaori T, Ito H, Schwarz EM, Tsutsumi R, Yoshitomi H, Oishi S, Nakano M, Fujii N, Nagasawa T, Nakamura T (2009) Stromal cell-derived factor 1/CXCR4 signaling is critical for the recruitment of mesenchymal stem cells to the fracture site during skeletal repair in a mouse model. Arthritis Rheum 60: 813-823.

Krebs MD, Sutter KA, Lin AS, Guldberg RE, Alsberg E (2009) Injectable poly(lactic-co-glycolic) acid scaffolds 
with in situ pore formation for tissue engineering. Acta Biomater 5: 2847-2859.

Leeuwenburgh SC, Jo J, Wang H, Yamamoto M, Jansen JA, Tabata Y (2010) Mineralization, biodegradation, and drug release behavior of gelatin/apatite composite microspheres for bone regeneration. Biomacromolecules 11: 2653-2659.

LeGeros RZ, Lin S, Rohanizadeh R, Mijares D, LeGeros JP (2003) Biphasic calcium phosphate bioceramics: preparation, properties and applications. J Mater Sci Mater Med 14: 201-209.

Loozen LD, van der Helm YJ, Öner FC, Dhert WJ, Kruyt MC, Alblas J (2015) Bone morphogenetic protein-2 nonviral gene therapy in a goat iliac crest model for bone formation. Tissue Eng Part A 21: 1672-1679.

Mladenovska K, Kumbaradzi E, Dodov G, Makraduli L, Goracinova K (2002) Biodegradation and drug release studies of BSA loaded gelatin microspheres. Int J Pharm 242: 247-249.

Otsuru S, Tamai K, Yamazaki T, Yoshikawa H, Kaneda Y (2008) Circulating bone marrow-derived osteoblast progenitor cells are recruited to the bone-forming site by the CXCR4/stromal cell-derived factor-1 pathway. Stem Cells 26: 223-234.

Park DJ, Choi JH, Leong KW, Kwon JW, Eun HS (2007) Tissue-engineered bone formation with gene transfer and mesenchymal stem cells in a minimally invasive technique. Laryngoscope 117: 1267-1271.

Poldervaart MT, Wang H, van der Stok J, Weinans H, Leeuwenburgh SC, Oner FC, Dhert WJ, Alblas J (2013) Sustained Release of BMP-2 in Bioprinted Alginate for Osteogenicity in Mice and Rats. PLoS ONE 8: e72610.

Ratanavaraporn J, Furuya H, Kohara H, Tabata Y (2011) Synergistic effects of the dual release of stromal cell-derived factor- 1 and bone morphogenetic protein-2 from hydrogels on bone regeneration. Biomaterials 32: 2797-2811.

Riley EH, Lane JM, Urist MR, Lyons KM, Lieberman JR (1996) Bone morphogenetic protein-2: biology and applications. Clin Orthop Relat Res: 39-46.

Rowley JA, Madlambayan G, Mooney DJ (1999) Alginate hydrogels as synthetic extracellular matrix materials. Biomaterials 20: 45-53.

Stevens MM, Marini RP, Schaefer D, Aronson J, Langer $\mathrm{R}$, Shastri VP (2005) In vivo engineering of organs: the bone bioreactor. Proc Natl Acad Sci U S A 102: 11450 11455.

Tierney EG, Duffy GP, Cryan SA, Curtin CM, O’Brien FJ (2013) Non-viral gene-activated matrices: next generation constructs for bone repair. Organogenesis 9: 22-28.

Wegman F, Bijenhof A, Schuijff L, Oner FC, Dhert WJ, Alblas J (2011) Osteogenic differentiation as a result of BMP-2 plasmid DNA based gene therapy in vitro and in vivo. Eur Cell Mater 21: 230-242.

Wegman F, van der Helm Y, Oner FC, Dhert W, Alblas J (2013) BMP-2 plasmid DNA as a substitute for BMP-2 protein in bone tissue engineering. Tissue Eng Part A 19: 2686-2692.

Wernike E, Montjovent MO, Liu Y, Wismeijer D, Hunziker EB, Siebenrock KA, Hofstetter W, Klenke
FM (2010) VEGF incorporated into calcium phosphate ceramics promotes vascularisation and bone formation in vivo. Eur Cell Mater 19: 30-40.

Young S, Wong M, Tabata Y, Mikos AG (2005) Gelatin as a delivery vehicle for the controlled release of bioactive molecules. J Control Release 109: 256-274.

Yuan H, Fernandes H, Habibovic P, de Boer J, Barradas AM, de Ruiter A, Walsh WR, van Blitterswijk CA, de Bruijn JD (2010) Osteoinductive ceramics as a synthetic alternative to autologous bone grafting. Proc Natl Acad Sci U S A 107: 13614-13619.

\section{Discussion with Reviewers}

(Scientific Editor in charge of the paper: Chris Evans)

Reviewer I: As addressed in the manuscript, in vitro release kinetics are a poor representation of the in vivo release, particularly when the in vitro studies do not evaluate the same constructs as those implanted in vivo. The in vitro studies should include the influence of the calcium phosphate microparticles, and the presence or absence of MSCs. Further, to truly understand the relevant release rates of SDF-1, the release profiles should be measured in vivo either through I-125 or fluorophore labelling. Use of the subcutaneous implant model should facilitate this analysis.

Authors: It is widely known and accepted in the field that in vitro release studies are most likely not representative for in vivo release of a given growth factor. Even ${ }^{125}$ I -labelling and fluorophore labelling do not qualify as reliable for in vivo measurements, as the growth factor may be (partly) degraded, while the label is still detectable. Nevertheless, comparisons between different concentrations and sizes of release particles used is very well possible in vitro, and this is exactly how we designed our constructs, in order to select a suitable concentration and reasonable timing.

In the past, we included calcium phosphate particles in alginate based construct, and observed no differences in release of BMPs (results not shown).

Reviewer I: To make conclusions regarding vascular growth and inflammation, specific immunohistochemistry must be evaluated. Appropriate vessel markers include: CD45 - /CD31 +, Isolectin B4, or vWF. Similarly, appropriate inflammatory cell markers include: F4/80 or CD68 (macrophages), CD3 (lymphocytes), CD45 (common leukocyte), and CD11b (monocyte/macrophages). These may be imaged by immunofluorescence and pseudoquantified by image analysis for group comparisons.

Authors: Although we refer to published work, also by our group, concerning vasculogenic properties of SDF-1, no conclusions to vascular ingrowth or inflammation are put forward in this manuscript. The main outcome of this study was bone formation after 6 weeks of implantation, at which time point differences in vascular density are no longer detectable in this small animal model.

Reviewer II: Animals are harvested 6 weeks after implantation, but release of SDF 1a is only measured over 
19 days. What is the release profile over the 2 nd three weeks of the experiment?

Authors: In this study, our aim was to release SDF-1 $\alpha$ in a relatively fast manner. As we know from literature, the need for construct vascularisation is immediate, and therefore we chose GMPs that would release the full amount of SDF-1 $\alpha$ in several days. Since we know in vivo release is faster than in vivo release (also mentioned in discussion), the release from the vehicle we tested is very suitable. We did not proceed the experiment for the later weeks since release was near zero, and of no further clinical relevance.

Reviewer II: Can you please comment on the possible effects of the proposed delivery mechanisms of BMP2 on the host?
Authors: In this study BMP-2 plasmid DNA is non-virally delivered in an alginate hydrogel which acts as a gene activated matrix (GAM). This methodology allows plasmid DNA uptake by adjacent cells, but it is not integrated into the genome, and will induce a transient expression of BMP-2. As soon as the encoding DNA, or the produced protein, enters the bloodstream, degradation will occur within minutes, ensuring a localised and therefore low risks strategy. 